\title{
Helping babies breathe: Providing an evidence-based education intervention at a tertiary referral hospital in Liberia
}

\author{
Cynthia Bondoe ${ }^{1}$, Ada Brown Wraynee ${ }^{1}$, Mary E. Riner ${ }^{2}$, Eman Allam ${ }^{2,3}$, Evelyn Stephenson ${ }^{2}$ \\ 1. Tubman National Institute of Medical Arts, Monrovia, Liberia. 2. Indiana University Purdue University Indianapolis, \\ Indiana, USA. 3. National Research Centre, Cairo, Egypt.
}

Correspondence: Mary E. Riner. Address: Indiana University School of Nursing, 1111 Middle Drive, NU117, Indianapolis, IN 46202, Indiana, USA. Email: mriner@iu.edu

Received: April 28, 2014

Accepted: J une 23, 2014

Online Published: July 22, 2014

DOI : $10.5430 /$ jnep.v4n9p119

URL: http://dx.doi.org/10.5430/jnep.v4n9p119

\section{Abstract}

Background: Helping Babies Breathe (HBB) is a neonatal resuscitation program that utilizes an active learning pedagogy to increase knowledge and skills for nurses and midwives in resource-limited areas. Two faculty members from the Tubman National Institute of Medical Arts in Liberia became certified as HBB trainers while completing a graduate nurse educator degree in the US. The aim of the current study was to use an academic program requirement for a graduate practicum and research experience to determine the effect of implementing the HBB program on the level of neonatal resuscitation knowledge and skills of students and staff at the John F. Kennedy Medical Center (JFKMC) in Liberia.

Methods: The HBB program was provided to 154 participants from the JFKMC and the co-located Tubman National Institute of Medical Arts for a period of six weeks. Assessment of the participants' neonatal resuscitation skills and knowledge included pre/post scores on multiple choice questions and evaluation of the bag and mask ventilation skills using an objective structured clinical examination (OSCE) approach.

Results: Participants expressed satisfaction with the program and the skills acquired. A paired t test for the multiple choice items indicated significant knowledge difference between the pretest $(2.36 \pm 2.21)$ and posttest $(15.27 \pm 1.24)$ scores, $p$ $=.000$. On the skills checklist for OSCE A, all participants achieved final competency rates of $100 \%$ on six items, $90 \%$ $99 \%$ on two, $70 \%-79 \%$ on one, and $<69 \%$ on four items; on OSCE B, they achieved final competency rates of $100 \%$ on 12 checklist items, $90 \%-99 \%$ on one, $80 \%-89 \%$ on three, $70 \%-79 \%$ on one, and $<69 \%$ on one item.

Conclusions: Implementing the HBB training is an important initial step in providing delivery room staff with the skills and knowledge to reduce neonatal mortality from asphyxia. The training needs to be supplemented with additional, ongoing practice and institutional support. The model of allowing internationally educated nurses completing graduate nurse educator degrees in the US to complete practicum and research requirements at their home institution was successful. Nurse and midwifery faculty who are certified in providing the HBB can effectively provide this training. We recommend that HBB training be provided in all health care facilities in developing countries with high neonatal mortality rates.

\section{Key words}

Helping Babies Breathe, Neonatal resuscitation, Liberia 


\section{Introduction}

Each year, childbirth complications result in about 814.000 neonatal deaths and 1.02 million stillbirths worldwide. Out of 7.7 million deaths of children under age five years, 3.1 million are neonatal deaths ${ }^{[1,2]}$. Almost all of these deaths are in low- and middle-income countries, where women frequently lack access to quality perinatal care and may delay careseeking ${ }^{[3,4]}$. The most common causes of neonatal mortality are thought to be pre-term birth complications (12\%), birth asphyxia (9\%), sepsis (6\%), and pneumonia (4\%) ${ }^{[2]}$. Mortality rates are significantly affected by the quality of in-hospital care for the neonate. Among the most simple, affordable, and effective strategies available for low-resource settings is the Helping Babies Breathe ${ }^{\circledR}$ (HBB) program, a neonatal resuscitation training program aiming to increase skilled birth attendance ${ }^{[5]}$.

HBB is a life support program developed by the American Academy of Pediatrics in collaboration with other agencies such as the WHO; National Institute of Child Health and Development (NICHD); United States Agency for International Development (USAID); Saving Newborn Lives, International Liaison Committee on Resuscitation (ILCOR); and other public and private globally minded organizations. It is designed to train birth attendants in developing countries on the essential skills of newborn resuscitation (Steele, 2013). The study by Singhal et al. (2012) indicated that application of the HBB skills by trained health practitioners helps to save lives and gives a much better start to those babies who struggle to breathe at birth ${ }^{[5]}$.

Globally, Liberia has been ranked among the world's most challenged in regard to high under-five and infant mortalities ${ }^{[6]}$. According to the Liberia Demographic Health Survey ${ }^{[7]}$, Liberia neonatal mortality rate is $32 / 1,000$ live births, infant mortality rate is 72/1,000 live births, and under-five mortality rate is 110/1,000 live births. In 2010, the number of neonatal deaths in Liberia before 28 days of age was estimated to be $34 / 1,000$ live births ${ }^{[8]}$.

Liberia is a low-resource post-conflict country with a high neonatal mortality rate. The period of 14 years of instability and war, which devastated Liberia's health and socio-economic infrastructure, resulted in a sharp increase in newborn babies' deaths. This was partly due to expatriation or relocation of trained clinicians, looting and destruction of health facilities, disruption of supply chains, and extended interruption of training in medical and nursing/midwifery schools. It greatly affected basic public health services at hospitals, health centers, and clinics, and it limited availability of electricity and potable water, which led to further health problems ${ }^{[9]}$.

In 2005, peace was restored to Liberia. The early recovery phase was focused on strategies to build peace and security, revitalize the economy, strengthen governance and rule of law, and deliver a set of basic health services. It later required the repair of many physical building to increase availability of health services. Training institutions had to be reopened and the work force expanded significantly to replace the trained clinicians who had fled or had been killed. Maternal and Newborn Health was gradually recognized as a priority area and the Ministry of Health \& Social Welfare developed several policy documents such as the Road Map for Maternal and Newborn Mortality Reduction to address the challenges affecting both maternal and newborn health ${ }^{[9]}$.

The investigators believed it was important for all nurses, midwives, and students attending births to have the essential knowledge and skills to assess newborns' breathing status and effectively respond as needed. It had been noted that staff failed to recognize breathing difficulty early, and most of the time they did not assess and take immediate action to resuscitate non-breathing babies at the time of delivery. Priority was often given to the mother's needs. The baby was often laid on a nearby table for several minutes with little attention. This problem could be partly attributed to not having a staff member present who was dedicated to the newborn.

Although the burden of neonatal deaths is of utmost importance in the low- and middle-income countries with the greatest neonatal mortality and stillbirth rates, coverage of skilled birth attendance is scarce in these countries ${ }^{[8]}$. With the objective of achieving Millennium Development Goals 4 and 5 to reduce neonatal deaths by increasing coverage of skilled 
birth attendants and improving the quality of obstetrical and perinatal care ${ }^{[10]}$, the JFKMC decided to provide the HBB training for staff. In this work, we investigated the impact of implementing the HBB educational program on the level of neonatal resuscitation knowledge and skills of the involved staff at the John F. Kennedy Medical Center (JFKMC) in Liberia.

The JFKMC is located in Monrovia and is the teaching and referral hospital for Liberia. In addition, the Tubman National Institute of Medical Arts (TNIMA), the main training facility for mid-level health care providers, is also located there. As part of a US Agency for International Development grant to the University of Liberia and Indiana University, two nursing faculty members attended a graduate nursing education program in the US. Upon completion of their degrees, they led the newly established BSc in Nursing and BSc in Midwifery programs in Liberia. These programs were designed to articulate with the diploma programs offered at TNIMA and provide the first publicly available bachelor's-level education in Liberia.

\section{Methods}

\subsection{The sample and the setting}

The HBB training sessions were conducted over a period of six weeks at TNIMA in Liberia. The study sample consisted of 180 voluntary participants who were either JFKMC nurses and midwives or nursing, midwifery, or physician's assistant students from TNIMA. Out of this number, 71 were students and 109 were JFKMC staff. A total of 154 completed the HBB training and were certified. Twenty-six participants did not complete the HBB training program and were not certified. The 154 participants who completed the HBB training included 60 students (physician assistants, professional nursing students, or midwifery students) and 94 professional JFKMC staff.

\subsection{Description of the program}

The training sessions used a performance model approach. While the two TNIMA faculty members were in the US, they completed high-tech neonatal resuscitation training and also became certified to train the trainers for the HBB program. They served as the instructors for this program, and the experience was considered to be their graduate nursing education practicum and research study. Supervision for the practicum and research study was initially provided by a US faculty member and, throughout the program, by the CEO of JFKMC, who had a PhD in nursing. The training was conducted at the TNIMA. The sessions were offered in two four-hour blocks for each group. The sessions were conducted over a period of six weeks in order to accommodate all participants.

The HBB program was introduced and participants were trained on how to clear the airway and use a mask and ventilation bag to assist breathing. Each participant received an HBB learner workbook that included the information needed for the resuscitation process. It included visual links to the steps in the HBB Action Plan, the HBB Facilitator Flip Chart, and some additional resources and references. These resources provided participants with information and performance instructions such as the six case scenarios, recognizing danger signs, care of pre-term birth, technique for hand cleaning, and cleaning and testing of resuscitation equipment.

The subjects were divided into two groups of five to seven participants for the skills performance. In each group, participants took the respective roles of instructor, health provider, patient, helper, time keeper, and a researcher who reported skills performed and not performed. Those subjects who did not perform well had to go over the skills again until all the skills appeared to be mastered by all participants. Most participants demonstrated the skills by the second demonstration. At the end of each performance session, the participants came together in a bigger group for feedback and skill discussions. 


\subsection{Program evaluation and assessment tool}

The skills and knowledge assessment included examination by pre/post written multiple choice test questions and assessment of bag and mask ventilation skills. The Objective Structured Clinical Evaluation (OSCE) was used to examine the skills and decision-making, the initial steps in routine care, the skills of bag/mask ventilation, and assessment of the heart rate.

A pre- and posttest was administered to each subject at the beginning and end of the HBB training sessions. The pre- and posttest contains 17 multiple choice questions; each of the questions has four response options. The questions cover all content from birth preparation, routine care, the "golden minute", to continued ventilation. The golden minute is a key concept of the HBB. It indicates that within one minute or 60 seconds of birth, a baby should be breathing well or needs to be ventilated using a bag and mask.

The observation skills checklist included in the training material was the instrument used for assessing the HBB skills. This instrument contains facilitator instructions as to the method of conducting the observational skill checklist and was divided across two stations: A and B. The Station A checklist contained 13 items addressing the normal care of newborn, with content covering birth preparation, thorough drying of baby, recognition of baby not crying, and positioning and clearing baby airway. These contents are to be checked as done or not done while observing the subject performing the skills. Station B content begins by reviewing Station A, followed by the recognition of baby not breathing, observing chest movement, and improving ventilation. It contains 18 performance items to be checked as done or not done.

All data gathered were entered manually in spreadsheets for statistical analysis of the differences between the pre- and posttest results as well as the skills competency. The study took place in Liberia under supervision of faculty members from Indiana University School of Nursing (IUSON). The protocol was approved by the Indiana University Institutional Review Board (IRB) and the JFKMC Research Committee Board.

\section{Results}

One hundred and fifty-four participants were recruited and certified after voluntarily signing up and completing the eight credit-hour program. Staff and student learning were assessed and evaluated by the use of written multiple-choice pre- and posttests and OSCE A and B skills competencies forms.

A paired $t$ test was conducted to compare the pre- and posttest knowledge scores for the multiple choice items. There was a significant difference between the pretest $(2.36 \pm 2.21)$ and posttest $(15.27 \pm 1.24)$ scores, $p=.000$ (see Table 1$)$. Examples of knowledge items include: "When should the umbilical code be clamped or tied and cut during routine care"; "A baby is quiet, limp and not breathing at birth. What should you do?” and "What should you do in The Golden Minute?”.

Table 1. Pre- and Posttest scores data analysis, paired test results

\begin{tabular}{llllll}
\hline & Mean & SD & Maximum & Minimum & p-value \\
\hline Pre-test & 12.36 & 2.21 & 17 & 6 & $.000^{*}$ \\
Post-test & 15.27 & 1.24 & 17 & 10 & \\
\hline
\end{tabular}

*Significance was considered to be $p<.05$

Results from the skills competency analysis are presented in Tables 2 and 3. The skills included in OSCE A are those for routine care and are the first practice simulation students were asked to perform. The skills included in OSCE B are those needed for the golden minute when the bag and mask must be initiated and continued ventilation is required OSCE B also assesses taking action to seek advanced care and have parents informed of the situation. 
Table 2. Skill competency A Form

\begin{tabular}{|c|c|c|c|c|c|c|c|c|c|c|}
\hline \multirow[b]{2}{*}{$\begin{array}{l}\text { ITEM } \\
\text { NO. }\end{array}$} & \multirow[b]{2}{*}{ Item } & \multicolumn{3}{|c|}{ STUDENTS } & \multicolumn{3}{|c|}{ NURSES } & \multicolumn{3}{|c|}{ COMBINED (STUDENT \& NURSES) } \\
\hline & & Tally & $\begin{array}{l}\text { \% of } \\
\text { competency } \\
\text { achieve }\end{array}$ & $\begin{array}{l}\text { \% of } \\
\text { competency } \\
\text { not achieve }\end{array}$ & Tally & $\begin{array}{l}\text { \% of } \\
\text { competency } \\
\text { achieve }\end{array}$ & $\begin{array}{l}\text { \% of } \\
\text { competency } \\
\text { not achieve }\end{array}$ & Tally & $\begin{array}{l}\text { \% of } \\
\text { competency } \\
\text { achieve }\end{array}$ & $\begin{array}{l}\text { \% of } \\
\text { competency } \\
\text { not achieve }\end{array}$ \\
\hline & prepare for birth & & & & & & & & & \\
\hline 1 & $\begin{array}{l}\text { identify helper and } \\
\text { make emergency } \\
\text { plan }\end{array}$ & 10 & $33.33 \%$ & $66.67 \%$ & 47 & $100.00 \%$ & $0.00 \%$ & 57 & $74.03 \%$ & $25.97 \%$ \\
\hline 2 & $\begin{array}{l}\text { Prepare the area } \\
\text { for delivery }\end{array}$ & 30 & $100.00 \%$ & $0.00 \%$ & 47 & $100.00 \%$ & $0.00 \%$ & 77 & $100.00 \%$ & $0.00 \%$ \\
\hline 3 & $\begin{array}{l}\text { Clean hand and } \\
\text { maintain } \\
\text { technique }\end{array}$ & 5 & $16.67 \%$ & $83.33 \%$ & 30 & $63.83 \%$ & $36.17 \%$ & 35 & $45.45 \%$ & $54.55 \%$ \\
\hline 4 & $\begin{array}{l}\text { prepare area for } \\
\text { ventilation and } \\
\text { check equipment }\end{array}$ & 10 & $33.33 \%$ & $66.67 \%$ & 27 & $57.45 \%$ & $42.55 \%$ & 37 & $48.05 \%$ & $51.95 \%$ \\
\hline 5 & dries thoroughly & 30 & $100.00 \%$ & $0.00 \%$ & 47 & $100.00 \%$ & $0.00 \%$ & 77 & $100.00 \%$ & $0.00 \%$ \\
\hline 6 & remove wet cloth & 30 & $100.00 \%$ & $0.00 \%$ & 47 & $100.00 \%$ & $0.00 \%$ & 77 & $100.00 \%$ & $0.00 \%$ \\
\hline \multirow[t]{2}{*}{7} & $\begin{array}{l}\text { evaluate crying } \\
\text { recognize baby is } \\
\text { not crying }\end{array}$ & 30 & $100.00 \%$ & $0.00 \%$ & 47 & $100.00 \%$ & $0.00 \%$ & 77 & $100.00 \%$ & $0.00 \%$ \\
\hline & $\begin{array}{l}\text { clear airway and } \\
\text { stimulate } \\
\text { breathing }\end{array}$ & & & & & & & & & \\
\hline 8 & keep warm & 30 & $100.00 \%$ & $0.00 \%$ & 47 & $100.00 \%$ & $0.00 \%$ & 77 & $100.00 \%$ & $0.00 \%$ \\
\hline 9 & $\begin{array}{l}\text { position head and } \\
\text { clear airway }\end{array}$ & 20 & $66.67 \%$ & $33.33 \%$ & 30 & $63.83 \%$ & $36.17 \%$ & 50 & $64.94 \%$ & $35.06 \%$ \\
\hline \multirow[t]{2}{*}{10} & $\begin{array}{l}\text { stimulate by } \\
\text { rubing the back }\end{array}$ & 16 & $53.33 \%$ & $46.67 \%$ & 28 & $59.57 \%$ & $40.43 \%$ & 44 & $57.14 \%$ & $42.86 \%$ \\
\hline & $\begin{array}{l}\text { evaluate } \\
\text { breathing }\end{array}$ & & & & & & & & & \\
\hline 11 & $\begin{array}{l}\text { recognizes baby is } \\
\text { breathing well }\end{array}$ & 30 & $100.00 \%$ & $0.00 \%$ & 47 & $100.00 \%$ & $0.00 \%$ & 77 & $100.00 \%$ & $0.00 \%$ \\
\hline 12 & $\begin{array}{l}\text { clamps ties and cut } \\
\text { the cord }\end{array}$ & 25 & $83.33 \%$ & $16.67 \%$ & 47 & $100.00 \%$ & $0.00 \%$ & 72 & $93.51 \%$ & $6.49 \%$ \\
\hline 13 & $\begin{array}{l}\text { position skin to } \\
\text { skin and } \\
\text { communicate with } \\
\text { mother }\end{array}$ & 27 & $90.00 \%$ & $10.00 \%$ & 45 & $95.74 \%$ & $4.26 \%$ & 72 & $93.51 \%$ & $6.49 \%$ \\
\hline
\end{tabular}

Final OSCE A competency rates for students were as follows: $100 \%$ on six items; $90 \%-99 \%$ on one; $80 \%-89 \%$ on one; and $<69 \%$ on five items. Rates for staff members were: $100 \%$ on eight items; $90 \%-99 \%$ on one; and $<69 \%$ on four items. Combined student and staff OSCE A skills competency rates were $100 \%$ on six items; $90-99 \%$ on two; $70 \%-79 \%$ on one; and $<69 \%$ on four items.

Students achieved final competency rates on the OSCE B skills checklist of $100 \%$ on 12 items; $90 \%-99 \%$ on one; 80-89\% on three; and $<69 \%$ on two items. Staff achieved final competency rates on OSCE B of $100 \%$ on 12 items; $90-99 \%$ on one; 80\%-89\% on four; and 70\%-79\% on one item. For OSCE B, staff and students together achieved final competency rates of $100 \%$ on 12 items; $90 \%-99 \%$ on one; $80 \%-89 \%$ on three; $70 \%-79 \%$ on one; and $<69 \%$ on one item.

\section{Discussion}

By definition, early neonatal mortality refers to the death of a live-born baby within the first seven days of life, whereas late neonatal mortality covers the time after seven days until before 28 days. The sum of these two represents the neonatal mortality rate ${ }^{[11]}$. Studies have shown that HBB programs have been effective in reducing the neonatal mortality rates in many countries ${ }^{[5,12,13]}$. The HBB curriculum focuses on achieving spontaneous respiration or, when indicated, providing ventilation in the "golden minute," that is, ithin the first minute after birth for infants who do not begin to breathe on their 
own. Drying, clearing the airway, stimulation, and assisted ventilation with a self-inflating bag and mask and air are the basic steps of the resuscitation procedure ${ }^{[10]}$. This study investigated the impact of implementing the HBB educational program on the level of neonatal resuscitation knowledge and skills of the involved students and staff at the John F. Kennedy Medical Center (JFKMC) in Liberia.

Table 3. Skill competency B Form

\begin{tabular}{|c|c|c|c|c|c|c|c|c|c|c|}
\hline \multirow[b]{2}{*}{$\begin{array}{l}\text { ITEM } \\
\text { No. }\end{array}$} & \multirow[b]{2}{*}{ Item } & \multicolumn{3}{|c|}{ STUDENTS } & \multicolumn{3}{|c|}{ NURSES } & \multicolumn{3}{|c|}{ COMBINED } \\
\hline & & Tally & $\begin{array}{l}\% \text { of } \\
\text { competency } \\
\text { achieve }\end{array}$ & $\begin{array}{l}\% \text { of } \\
\text { competency } \\
\text { not achieve }\end{array}$ & Tally & $\begin{array}{l}\% \text { of } \\
\text { competency } \\
\text { achieve }\end{array}$ & $\begin{array}{l}\% \text { of } \\
\text { competency } \\
\text { not achieve }\end{array}$ & Tally & $\begin{array}{l}\% \text { of } \\
\text { competency } \\
\text { achieve }\end{array}$ & $\begin{array}{l}\% \text { of } \\
\text { competency } \\
\text { not achieve }\end{array}$ \\
\hline 1 & prepare for birth & 30 & $100.00 \%$ & $0.00 \%$ & 47 & $100.00 \%$ & $0.00 \%$ & 77 & $100.00 \%$ & $0.00 \%$ \\
\hline \multirow[t]{2}{*}{2} & $\begin{array}{l}\text { dries thoroughly } \\
\text { and remove wet } \\
\text { cloth }\end{array}$ & 30 & $100.00 \%$ & $0.00 \%$ & 47 & $100.00 \%$ & $0.00 \%$ & 77 & $100.00 \%$ & $0.00 \%$ \\
\hline & evaluate crying & & & & & & & & & \\
\hline \multirow[t]{2}{*}{3} & $\begin{array}{l}\text { recognizes baby is } \\
\text { not crying }\end{array}$ & 30 & $100.00 \%$ & $0.00 \%$ & 47 & $100.00 \%$ & $0.00 \%$ & 77 & $100.00 \%$ & $0.00 \%$ \\
\hline & $\begin{array}{l}\text { clear airway and } \\
\text { stimulate } \\
\text { breathing } \\
\text { keep warm, } \\
\text { position head, } \\
\text { clear airway } \\
\text { stimulate }\end{array}$ & 30 & $100.00 \%$ & $0.00 \%$ & 47 & $100.00 \%$ & $0.00 \%$ & 77 & $100.00 \%$ & $0.00 \%$ \\
\hline \multirow[t]{2}{*}{5} & $\begin{array}{l}\text { breathing by } \\
\text { rubing the back }\end{array}$ & 28 & $93.33 \%$ & $6.67 \%$ & 46 & $97.87 \%$ & $2.13 \%$ & 74 & $96.10 \%$ & $3.90 \%$ \\
\hline & $\begin{array}{l}\text { evaluate } \\
\text { breathing } \\
\text { recognizes baby is } \\
\text { not breathing }\end{array}$ & 30 & $100.00 \%$ & $0.00 \%$ & 47 & $100.00 \%$ & $0.00 \%$ & 77 & $100.00 \%$ & $0.00 \%$ \\
\hline 6 & $\begin{array}{l}\text { ventilate with bag } \\
\text { and mask } \\
\text { cut cord and move }\end{array}$ & & & & & & & & & \\
\hline 7 & $\begin{array}{l}\text { to area of } \\
\text { ventilation }\end{array}$ & 25 & $83.33 \%$ & $16.67 \%$ & 42 & $89.36 \%$ & $10.64 \%$ & 67 & $87.01 \%$ & $12.99 \%$ \\
\hline 8 & $\begin{array}{l}\text { start ventilation in } \\
\text { the golden minute } \\
\text { ventilate at } 40\end{array}$ & 20 & $66.67 \%$ & $33.33 \%$ & 40 & $85.11 \%$ & $14.89 \%$ & 60 & $77.92 \%$ & $22.08 \%$ \\
\hline 9 & $\begin{array}{l}\text { birth -min(30-50 } \\
\text { acceptable) }\end{array}$ & 30 & $100.00 \%$ & $0.00 \%$ & 47 & $100.00 \%$ & $0.00 \%$ & 77 & $100.00 \%$ & $0.00 \%$ \\
\hline \multirow[t]{2}{*}{10} & $\begin{array}{l}\text { looks for chest } \\
\text { movement }\end{array}$ & 30 & $100.00 \%$ & $0.00 \%$ & 47 & $100.00 \%$ & $0.00 \%$ & 77 & $100.00 \%$ & $0.00 \%$ \\
\hline & $\begin{array}{l}\text { evaluate } \\
\text { breathing } \\
\text { recognizes baby is } \\
\text { not breathing }\end{array}$ & 30 & $100.00 \%$ & $0.00 \%$ & 47 & $100.00 \%$ & $0.00 \%$ & 77 & $100.00 \%$ & $0.00 \%$ \\
\hline 12 & calls for help & 30 & $100.00 \%$ & $0.00 \%$ & 47 & $100.00 \%$ & $0.00 \%$ & 77 & $100.00 \%$ & $0.00 \%$ \\
\hline 13 & $\begin{array}{l}\text { continues } \\
\text { ventilation }\end{array}$ & 10 & $33.33 \%$ & $66.67 \%$ & 37 & $78.72 \%$ & $21.28 \%$ & 47 & $61.04 \%$ & $38.96 \%$ \\
\hline \multirow[t]{2}{*}{14} & $\begin{array}{l}\text { improves } \\
\text { ventilation }\end{array}$ & 30 & $100.00 \%$ & $0.00 \%$ & 47 & $100.00 \%$ & $0.00 \%$ & 77 & $100.00 \%$ & $0.00 \%$ \\
\hline & $\begin{array}{l}\text { evaluates } \\
\text { breathing and } \\
\text { heart rate }\end{array}$ & & & & & & & & & \\
\hline 15 & $\begin{array}{l}\text { recognizes baby is } \\
\text { not breathing, but } \\
\text { heart rate is } \\
\text { normal }\end{array}$ & 30 & $100.00 \%$ & $0.00 \%$ & 47 & $100.00 \%$ & $0.00 \%$ & 77 & $100.00 \%$ & $0.00 \%$ \\
\hline 16 & $\begin{array}{l}\text { continues } \\
\text { ventilation } \\
\text { recognizes baby is }\end{array}$ & 25 & $83.33 \%$ & $16.67 \%$ & 40 & $85.11 \%$ & $14.89 \%$ & 65 & $84.42 \%$ & $15.58 \%$ \\
\hline 17 & $\begin{array}{l}\text { breathing and } \\
\text { heart rate is } \\
\text { normal }\end{array}$ & 30 & $100.00 \%$ & $0.00 \%$ & 47 & $100.00 \%$ & $0.00 \%$ & 77 & $100.00 \%$ & $0.00 \%$ \\
\hline 18 & $\begin{array}{l}\text { stops ventilation; } \\
\text { monitors baby and } \\
\text { communicate with } \\
\text { mother }\end{array}$ & 25 & $83.33 \%$ & $16.67 \%$ & 40 & $85.11 \%$ & $14.89 \%$ & 65 & $84.42 \%$ & $15.58 \%$ \\
\hline
\end{tabular}


Significant knowledge gains were demonstrated by students and staff on the critical competencies identified in the HBB program. On the OSCE A skills demonstration, nine of the 13 (70\%) competencies were demonstrated by at least $80 \%$ of the students and staff. The five competencies below $80 \%$ included: identify helper and emergency plan; clean hands and maintain technique; prepare area for ventilation and check equipment; position head and clear airway; and stimulate breathing by rubbing back. Ongoing work in additional lab sessions and the actual delivery room will be important to improve these outcomes and achieve maximum benefit from the training.

On the skills demonstration for OSCE B, 16 of the 18 (89\%) competencies were demonstrated by at least $80 \%$ of the students and staff. The two items below 80\% included: start ventilation in the golden minute and continue for a non-breathing neonate. These are critical skills and, as with OSCE A skills, ongoing work in additional lab sessions and the actual delivery room will be important to address these deficiencies and sto achieve maximum benefit from the training.

In the present study, both the professional staff and students achieved significant knowledge gains and demonstrated high levels of skill performance. As could be expected, the professional staff had higher percentages of achieved competencies than did the students, particularly in relation to resuscitation. This was not surprising since this was the students' first introduction to neonatal resuscitation techniques. By the second demonstration they achieved greater competency. Another explanation for this improvement is that participants had the opportunity to practice competencies on the A Form for a day and the next day recapped competencies on the A Form for better understanding before demonstrating competencies on the B Form.

Data from Table 1 revealed that both staff and students gained knowledge and skills considered critical for newborn resuscitation. In addition, comparing the (pre/posttest) scores using the paired $t$ test shows significant gains in knowledge for both students and staff.

The findings of the current study are consistent with those of Singhal et al. $2012^{[5]}$, who found that participants in the HBB program for neonatal resuscitation in two resource-limited settings (Kenya and Pakistan) demonstrated high satisfaction, high self-efficacy, and gains in knowledge and skills. They also reported that mastery of ventilation skills and integration of skills into case management may not be achievable in the classroom setting without additional practice, continued learning, and active mentoring in the workplace.

In order to assess the immediate use of HBB skills and knowledge, the investigators visited the Maternity Center delivery room two weeks after completing all the training sessions and reviewed records of babies born at the hospital. It was observed that midwives who attended the HBB training were applying the training skills. For example, one baby was born crying well and the midwife proceeded to drying and keeping this baby warm without suctioning. A record review was conducted for a period of three months of babies admitted to the neonatal unit. These records showed eight asphyxia deaths in the first month. In the second month, after the initiation of the program, there was one asphyxia death, and in the third there were seven. This is obviously too limited a period of time to evaluate the long-term effect of the program, but it does suggest that continuing reinforcement sessions may be needed. We plan to collect more effectiveness data. Knowledge and skills gained under simulated learning programs like the one presented in this study represent an important first step in changing practice behaviors. In addition to inservice education for staff and curriculum content for students, more work will be required for consistent adoption of these new skills into standard practice in the delivery room. Plans are currently underway to update skills through mini-inservices and real-time demonstration and correction by supervisions. Additional strategies include developing a policy/procedure for the delivery room and developing colorful visual learning aids of steps to be taken for resuscitation to post on the delivery room wall. Finally, a graduate doctoral student from the US University will conduct her research study on the hospital to further facilitate the full and consistent implementation of the HBB protocol. 
This study represents one of the first institution-level implementations of HBB in Liberia. It adds another country to those already providing this neonatal life-saving training program, and it is located at the major teaching and referral hospital for the country. Using the simple methodology developed by international neonatal experts and tailored to healthcare settings with very limited resources in many developing countries, Liberia now has trainers prepared to spread this lifegiving intervention.

An additional important finding from the study was that students in a master's of nursing education program could effectively conduct HBB training sessions for staff and students working in a tertiary referral hospital in Monrovia. This was considered a new role for nurse and midwife faculty members at the hospital and was controversial since previously physicians had piloted the HBB training for a small group of staff and considered this training a physician's role. The results showed that nursing/midwifery faculty who are certified trainers can achieve results similar to other international HBB trainings provided in low to middle income countries ${ }^{[5]}$. This is an important outcome because it extends the availability of trainers prepared to provide the HBB program throughout Liberia. The general administrator of the hospital subsequently recommended to the Minister of Health and Social Welfare that these two nursing faculty members be engaged to train midwives in community health facilities throughout the country in order to address the need to improve neonatal resuscitation in rural areas.

\section{Conclusion}

In this study the Helping Babies Breathe program was provided to students and staff at the teaching and referral hospital in Liberia, a post-conflict, low income country. The program was provided by two Liberian faculty members who were graduate nursing education major students in the US and were certified as trainers to deliver the program. By conducting their master's practicum and research study at their home institution, the faculty members were able to address an important Millennial Development Goal and a major health problem facing the country.

Results showed a significant increase in neonatal knowledge as well as attainment of skills by staff and students. It is expected that full implementation will include establishing agency procedures, supervision, and support to staff in the delivery room and will ultimately result in lower neonatal mortality due to asphyxia. Plans are underway to provide the HBB training in rural areas throughout the country.

Similar institutions seeking to implement the HBB program should fully support the initial training initiative and plan for ongoing implementation support. Preparing nurses and midwives as certified trainers can make this valuable lifesaving knowledge and skill available to those delivering babies under high risk conditions in low resource areas.

\section{References}

[1] Lawn JE, Shibuya K, Stein C. No cry at birth: global estimates of intrapartum stillbirths and intrapartum-related neonatal deaths. Bulletin of the World Health Organization. 2005; 83(6): 409-417. http://dx.doi.org/10.1590/S0042-96862005000600008

[2] Black RE, Cousens S, Johnson HL, Lawn JE, Rudan I, Bassani DG, Mathers C. Global, regional, and national causes of child mortality in 2008: a systematic analysis. The lancet. 2010; 375(9730): 1969-1987. http://dx.doi.org/10.1016/S0140-6736(10)60549-1

[3] Goldenberg RL, McClure EM, Bann CM. The relationship of intrapartum and antepartum stillbirth rates to measures of obstetric care in developed and developing countries. Acta obstetricia et gynecologica Scandinavica. 2007; 86(11): 1303-1309. PMid:17963057 http://dx.doi.org/10.1080/00016340701644876

[4] Lawn JE, Lee AC, Kinney M, Sibley L, Carlo WA, Paul VK, Darmstadt GL. Two million intrapartum-related stillbirths and neonatal deaths: where, why, and what can be done? International Journal of Gynecology \& Obstetrics. 2009; 107: S5-S19. http://dx.doi.org/10.1016/j.ijgo.2009.07.016

[5] Singhal N, Lockyer J, Fidler H, Keenan W, Little G, Bucher S, Niermeyer S. Helping Babies Breathe: global neonatal resuscitation program development and formative educational evaluation. Resuscitation. 2012; 83(1): 90-96.

http://dx.doi.org/10.1016/j.resuscitation.2011.07.010 
[6] Ahmad OB, Lopez AD, Inoue M. The decline in child mortality: a reappraisal. Bulletin of the World Health Organization. 2000; 78: 1175-1191. http://dx.doi.org/10.1590/S0042-96862000001000004

[7] Liberia Demographic and Health Survey 2007. Monrovia: Liberia Institute of Statistics and Geo-Information Services and ORC Macro; 2008

http://www.scielosp.org/scielo.php?script=sci_nlinks\&ref=320209\&pid=S0042-9686201000070001100024\&lng=en

[8] World Health Organization. World health statistics 2010.

[9] Situational Analysis of Newborn Health in Liberia, 2013. Publication USAID-GHS-A-00-08-00002-00 (MCHIP)

[10] Steele C. Helping Babies Breathe Around the World. Journal of Obstetric, Gynecologic, \& Neonatal Nursing. 2013; 42(2): 243-246. PMid:23373533 http://dx.doi.org/10.1111/1552-6909.12019

[11] Wall SN, Lee AC, Carlo W, Goldenberg R, Niermeyer S, Darmstadt GL, Lawn JE. Reducing intrapartum-related neonatal deaths in low-and middle-income countries—what works? Seminars in perinatology. 2010; 34(6): 395-407. http://dx.doi.org/10.1053/j.semperi.2010.09.009

[12] Goudar SS, Somannavar MS, Clark R, Lockyer JM, Revankar AP, Fidler HM, Singhal N. Stillbirth and newborn mortality in India after helping babies breathe training. Pediatrics. 2013; 131(2): e344-e352. PMid:23339215 http://dx.doi.org/10.1542/peds.2012-2112

[13] Msemo G, Massawe A, Mmbando D, Rusibamayila N, Manji K, Kidanto HL, Perlman J. Newborn mortality and fresh stillbirth rates in Tanzania after helping babies breathe training. Pediatrics. 2013; 131(2): e353-e360. PMid:23339223 http://dx.doi.org/10.1542/peds.2012-1795 